\title{
In vitro antimicrobial activities of cinnamon bark oil, anethole, carvacrol, eugenol and guaiazulene against Mycoplasma hominis clinical isolates
}

\author{
Radek Slehaa ${ }^{\mathrm{a}, \mathrm{b}}$, Petra Mosio ${ }^{\mathrm{a}}$, Marketa Vydrzalova ${ }^{\mathrm{a}}$, Alexandra Jantovska ${ }^{\mathrm{a}}$, Vanda Bostikova ${ }^{\mathrm{b}}$, Jaroslava Mazurova ${ }^{\mathrm{a}}$
}

\begin{abstract}
Aims. The aim of this study was to evaluate the antimicrobial effects of five natural substances against 50 clinical isolates of Mycoplasma hominis.

Methods and Results. The in vitro activity of selected natural compounds, cinnamon bark oil, anethole, carvacrol, eugenol and guaiazulene, was investigated against $50 \mathrm{M}$. hominis isolates cultivated from cervical swabs by the broth dilution method. All showed valuable antimicrobial activity against the tested isolates. Oil from the bark of Cinnamomum zeylanicum ( $\mathrm{MBC}_{90}=500 \mu \mathrm{g} / \mathrm{mL}$ ) however was found to be the most effective. Carvacrol $\left(\mathrm{MBC}_{90}=600 \mu \mathrm{g} / \mathrm{mL}\right.$ ) and eugenol $\left(\mathrm{MBC}_{90}=1000 \mathrm{\mu g} / \mathrm{mL}\right)$ also possessed strong antimycoplasmal activity.

Conclusions. The results indicate that cinnamon bark oil, carvacrol and eugenol have strong antimycoplasmal activity and the potential for use as antimicrobial agents in the treatment of mycoplasmal infections.
\end{abstract}

Key words: Mycoplasma hominis, antimicrobial agents, minimal inhibitory concentration, natural substances

Received: November 15, 2011; Accepted with revision: July 26, 2012; Available online: October 30, 2012

http://dx.doi.org/10.5507/bp.2012.083

${ }^{a}$ Department of Biology and Biochemistry, Faculty of Chemical Technology, University of Pardubice, Pardubice, Czech Republic ${ }^{b}$ Faculty of Military Health Sciences, University of Defence, Hradec Kralove

Corresponding author:Petra Mosio, e-mail:Petra.Mosio@upce.cz

\section{INTRODUCTION}

Mycoplasma (M.) hominis, the first human mycoplasma species ${ }^{1}$, has been isolated in the case of a variety of diseases, including bacterial vaginosis, pelvic inflammatory disease and pyelonephritis. In recent years, it has been reported with increasing frequency to cause complicated pregnancies, chorioamnionitis, postabortion and postpartum fevers ${ }^{2-4}$. In addition, it has been implicated in extragenital infections such as postoperative wound infections, arthritis, prosthetic valve endocarditis, respiratory and other infections in immunosuppressed patients ${ }^{5}$. In neonates, $M$. hominis has been associated with neonatal meningitis, pneumonia and skin abscesses ${ }^{6-9}$.

Mycoplasmas are naturally resistant to antibiotic compounds that are directed to inhibition of cell wall synthesis, such as penicillins and cephalosporins ${ }^{2,7}$. Moreover, they are generally resistant to polymyxins, rifampicin and sulphonamides ${ }^{7}$. Therefore, treatment options for mycoplasmal infections are limited to relatively few classes of antimicrobial agents, tetracyclines, macrolides, quinolones and related antibiotics.

Increasing incidence of antimicrobial resistance as a result of overprescription and misuse of traditional antibiotics is a growing concern in medical, food and sanitation areas. To reverse high resistance frequencies, substantial resources have been invested in the research of new antimicrobial substances, mainly of microbial and plant origin. To our knowledge, few studies of the antimicrobial susceptibility of M. hominis to natural substances have been reported. The antimycoplasmal effects of hydroxytyrosol and oleuropein (major phenolic compounds identified in olive oil) and of tea tree oil have been determined $^{10-13}$.

The aim of this study was to examine the in vitro susceptibilities of $M$. hominis clinical isolates to several natural substances derived from plants.

\section{MATERIALS AND METHODS}

\section{Bacterial strains}

The M. hominis isolates studied included 50 strains cultivated from the cervical swabs of randomly selected women between 2003 and 2004. M. hominis strains were stored at $-80{ }^{\circ} \mathrm{C}$. Before performing experiments, strains were thawed and retrieved by transfer into PPLO broth at $37^{\circ} \mathrm{C}$ for $24 \mathrm{~h}$. The bacterial inoculum of $10^{5}-10^{7} \mathrm{CFU} /$ $\mathrm{mL}$ was prepared as described previously ${ }^{14}$.

\section{Culture media}

M. hominis strains were cultivated in PPLO broth. The following composition is given for the preparation of one litre of medium: $21 \mathrm{~g}$ BD Difco ${ }^{\mathrm{TM}}$ PPLO broth (BD Diagnostics), $200 \mathrm{~mL}$ horse serum (LabMediaServis, Jaromer, Czech Republic), $100 \mathrm{~mL}$ freshly-prepared yeast extract, $8 \mathrm{~mL} \mathrm{10 \%}$ thallium acetate (Sigma-Aldrich), $1 \mathrm{~g}$ ampicillin (Biotika Bohemia, Prague, Czech Republic), $5 \mathrm{~g}$ L-arginine and $2 \mathrm{~mL} \mathrm{1 \%}$ phenol red (both Sigma-Aldrich) and $700 \mathrm{~mL}$ of purified water. Antimicrobial susceptibility testing was performed in PPLO broth without inhibitors (ampicillin and thallium acetate). PPLO agar was prepared from $35 \mathrm{~g}$ of BD Difco ${ }^{\mathrm{TM}}$ PPLO agar (BD Diagnostics) and supplemented the same way as PPLO broth. 
Natural substances

All natural substances (anethole, carvacrol, cinnamon bark oil, eugenol and guaiazulene) were purchased from Sigma-Aldrich and were extended in $24 \%$ ethanol to obtain stock solutions.

\section{Antimicrobial susceptibility testing}

The antimicrobial effects of the selected substances were determined by the broth dilution method. Serial twofold dilutions of anethole, cinnamon bark oil, eugenol and quaiazulene in a concentration range $62.5-4000 \mu \mathrm{g} / \mathrm{mL}$ and carvacrol in a concentration range $18.75-1200 \mu \mathrm{g} /$ $\mathrm{mL}$ were prepared (Table 1 ). Each tube with $1 \mathrm{~mL}$ PPLO broth containing tested substances was inoculated with $100 \mu \mathrm{L}$ of the standardized inoculum and incubated aerobically at $37^{\circ} \mathrm{C}$. A positive growth control consisting of organisms in broth and a negative sterility control consisting of uninoculated broth were included for each assay. Inoculated tubes were examined daily until a colour change was detected in the positive control tube. The minimal inhibitory concentration $\left(\mathrm{MIC}_{90}\right)$ was defined as the lowest concentration of natural substance in which the metabolism of $90 \%$ of tested organisms was inhibited. This was evidenced by a lack of a colour change in the medium at the time when the positive growth control first showed a colour change. For $M$. hominis, growth was usually evident in the positive control after 24-48 h of incubation. Substances that showed inhibitory activity were further submitted to a subculture of the broth media on PPLO agar in order to evaluate bacterial growth. The concentration at which there was no bacterial growth of 90\% tested strains after inoculation on PPLO agar was taken as the minimal bactericidal concentration $\left(\mathrm{MBC}_{90}\right)$. When the $\mathrm{MIC}_{90}$ was greater than the highest tested concentration, the strain was considered as resistant.

\section{RESULTS}

The $\mathrm{MIC}_{90}$ and $\mathrm{MBC}_{90}$ results of all natural substances were determined (Table 1). Cinnamon bark oil, carvacrol, eugenol and anethole all were variously able to inhibit the growth of M. hominis clinical isolates (Fig.1A-E). Cinnamon bark oil was found to be the most effective natural substance tested against $M$. hominis $\left(\mathrm{MIC}_{90}=\right.$ $\left.\mathrm{MBC}_{90}=500 \mu \mathrm{g} / \mathrm{mL}\right)$. Carvacrol also possessed strong antimicrobial activity against $M$. hominis strains in this study with $\mathrm{MIC}_{90}$ and $\mathrm{MBC}_{90}$ equal to $600 \mu \mathrm{g} / \mathrm{mL}$. A somewhat lower value was determined for eugenol $\left(\mathrm{MIC}_{90}=\right.$ $\left.\mathrm{MBC}_{90}=1000 \mu \mathrm{g} / \mathrm{mL}\right)$. The antimycoplasmal activity of anethole was one of the lowest $\left(\mathrm{MIC}_{90}=\mathrm{MBC}_{90}=4000\right.$ $\mu \mathrm{g} / \mathrm{mL})$. The least effective natural substance was found to be guaiazulene with as much as $50 \%$ of resistant strains to the concentration $4000 \mu \mathrm{g} / \mathrm{mL}$ which was the highest concentration tested.

\section{DISCUSSION}

A variety of medicinal plants and plant extracts have been screened for their antimicrobial activity but to our best knowledge, the inhibitory effects of only oleuropein, hydroxythyrosol and tea tree oil have been tested against $M$. hominis strains ${ }^{10-13,15}$. In contrary to these studies we have determined lower antimycoplasmal activities of natural substances used in our work.

In the present study, $M$. hominis strains were highly sensitive to cinnamon bark oil with $\mathrm{MIC}_{90}=\mathrm{MBC}_{90}$ equal to $500 \mu \mathrm{g} / \mathrm{mL}$. As described previously, (E)-cinnamaldehyde is the major component $(97.7 \% \mathrm{w} / \mathrm{w})$ of the oil derived from Cinnamomum zeylanicum ${ }^{16}$. A number of biological activities including antioxidant, antipyretic, analgesic, antifungal and antibacterial have been attributed to this substance. The antimicrobial effect of cinnamaldehyde is related to its ability to bind to proteins preventing the action of amino acid decarboxylases ${ }^{17}$. It has been demonstrated that Cinnamomum zeylanicum oil has an inhibitory effect against a large variety of pathogenic microorganisms, including Haemophilus influenzae, Streptococcus pyogenes, Streptococcus pneumoniae, Staphylococcus aureus and Escherichia coli ${ }^{18}$.

Strong antimicrobial activity $\left(\mathrm{MIC}_{90}=\mathrm{MBC}_{90}=\right.$ $600 \mu \mathrm{g} / \mathrm{mL}$ ) was also determined for carvacrol, a phenolic compound isolated from leaves and flowers of Thymus vulgaris L. and Origanum vulgare. Carvacrol has several biological properties, particularly antioxidant and antimicrobial activity. The antimicrobial action of carvacrol is similar to other phenolic substances: damage of the cyto-

Table 1. In vitro antimicrobial activity of selected natural substances against $M$. hominis clinical isolates $(\mathrm{n}=50)$.

\begin{tabular}{lcccc}
\hline \multirow{2}{*}{ Natural substances } & \multicolumn{2}{c}{ Concentration range } & ${\mathrm{MIC} \text { and } \mathrm{MBC}^{\mathrm{a}}}$ \\
\cline { 3 - 4 } & & $\mathrm{MIC}_{90} \mathrm{~b}^{\mathrm{b}}$ & $\mathrm{MBC}_{90} \mathrm{c}^{\mathrm{C}}$ & $1000-4000$ \\
\hline Anethole & $62.5-4000$ & 4000 & 4000 & 1000 \\
Eugenol & $62.5-4000$ & 1000 & 1000 & $2000->4000$ \\
Guaiazulene & $62.5-4000$ & $>4000$ & $>4000$ & $300-600$ \\
Carvacrol & $18.75-1200$ & 600 & 600 & $250-1000$ \\
Cinnamon oil & $62.5-4000$ & 500 & 500 & \\
\hline
\end{tabular}

${ }^{\mathrm{a}} \mathrm{MIC}_{90}$ and $\mathrm{MBC}_{90}$ values are in $\mu \mathrm{g} / \mathrm{mL}$

${ }^{\mathrm{b}} \mathrm{MIC}_{90}$ is the lowest concentration of antimicrobial agent inhibiting metabolism of $90 \%$ tested strains

${ }^{\mathrm{c}} \mathrm{MBC}_{90}$ is the lowest concentration of antimicrobial agent inhibiting growth of $90 \%$ tested strains 
A Anethole MIC distribution

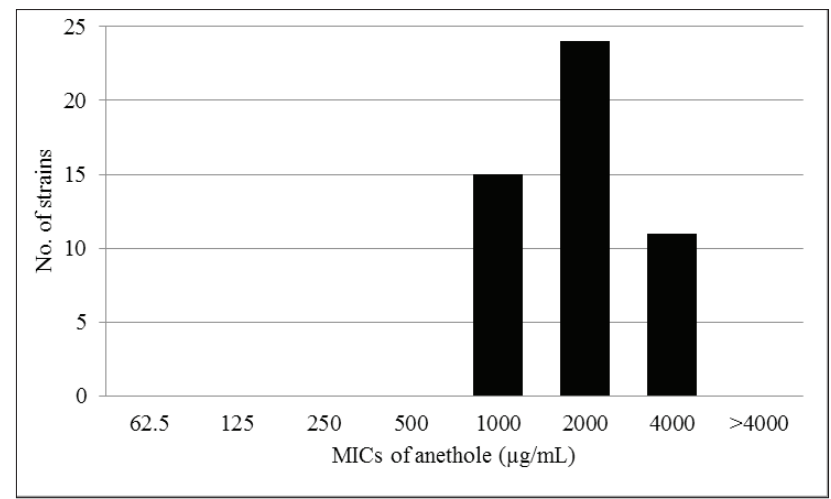

\section{Cinnamon oil MIC distribution}

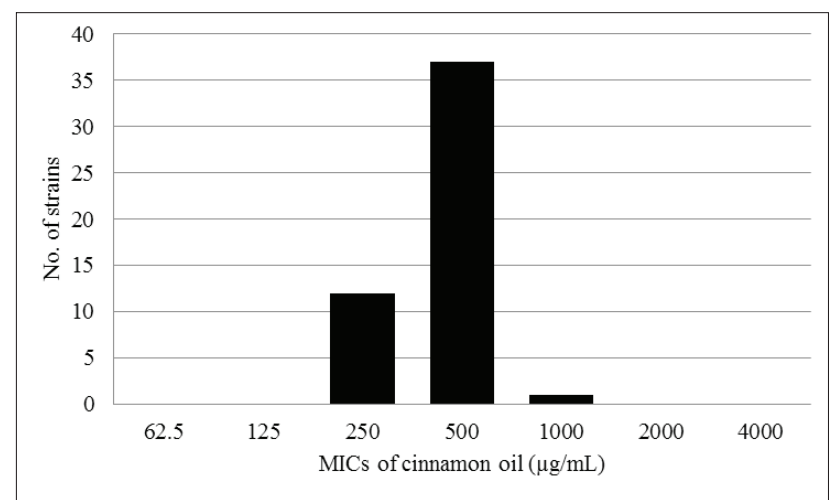

B Carvacrol MIC distribution

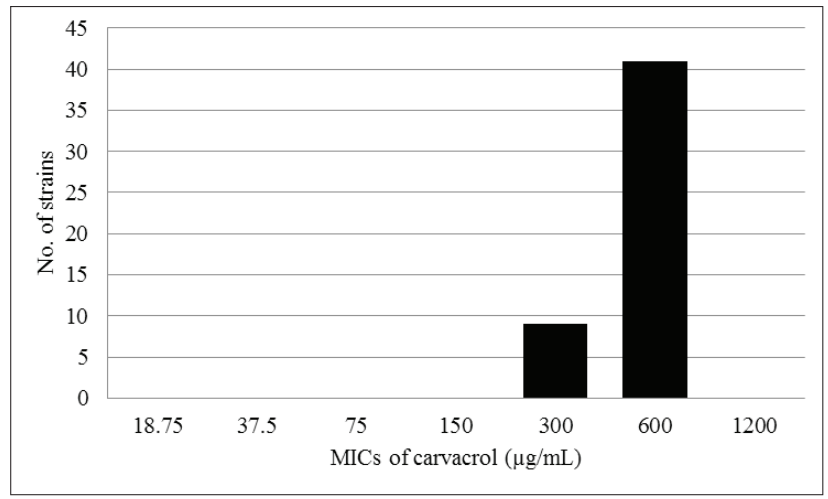

D Eugenol MIC distribution

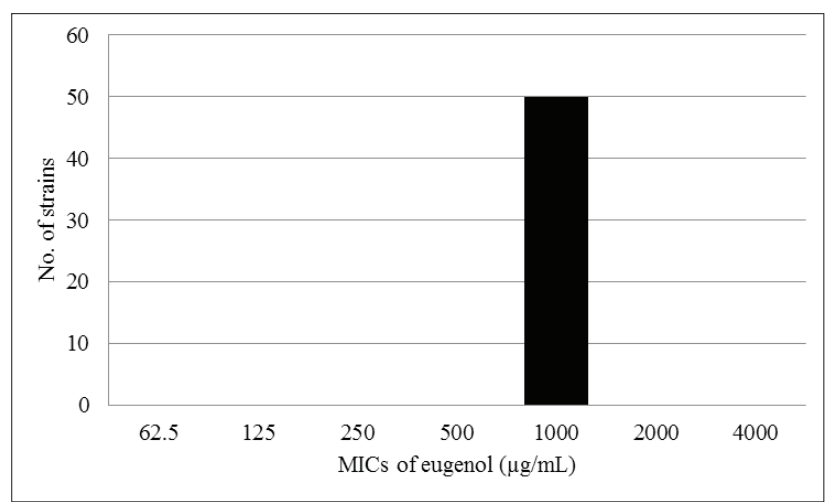

E Guaiazulene MIC distribution

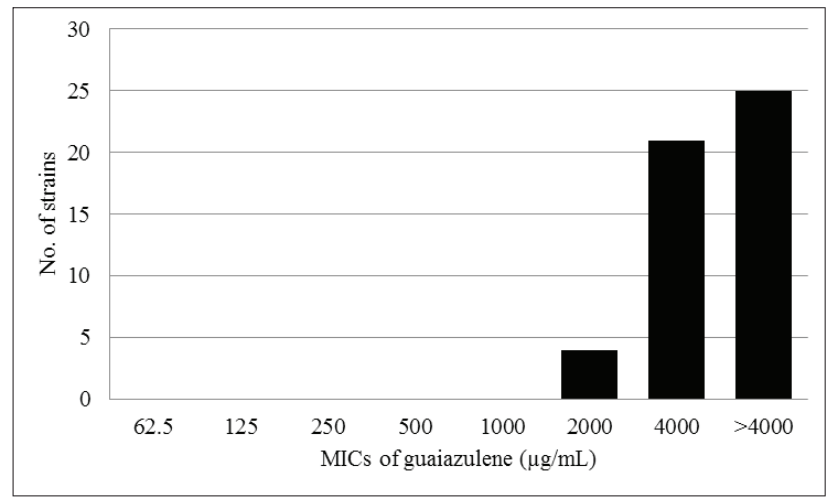

Fig. 1A-E. Distributions of MICs of anethole (A), carvacrol (B), cinnamon oil (C), eugenol (D) and guaiazulene (E) for M. hominis clinical isolates $(n=50)$.

plasmic membrane, disruption of the proton motive force, electron flow, active transport and coagulation of cell contents ${ }^{17}$. Carvacrol has been reported to possess inhibitory activity against Pseudomonas fluorescens, Escherichia coli, Staphylococcus aureus, Bacillus subtilis and Saccharomyces cerevisiae $^{19,20}$.

Eugenol, a major ingredient of the essential oil isolated from Syzygium aromaticum L., showed a lower efficiency than carvacrol $\left(\mathrm{MIC}_{90}=\mathrm{MBC}_{90}=1000 \mu \mathrm{g} / \mathrm{mL}\right)$. Eugenol has pronounced analgesic properties. In recent years, additional biological properties of this substance have been determined including fungicidal, bactericidal, antioxidant and anti-inflammatory properties ${ }^{21}$. The mechanism of the antimicrobial effect of eugenol has been studied recently. It was observed that treatment of Escherichia coli, Listeria monocytogenes and Lactobacillus sakei with this agent inhibited generation of adenosine triphosphate and caused cell membrane disruption ${ }^{22}$.

In the present study, anethole and guaiazulene were the least effective natural substances against $M$. hominis strains. The antimicrobial properties of these substances were probably affected by their poor solubility in ethanol.

The critical aspect of mycoplasma infections is their problematic eradication either due to the acquired resist- 
ance or due to lack of bactericidal activity. Tetracyclines have been the drug of choice for treatment of $M$. hominis urogenital infections. However, tetracycline resistance associated with transposon-borne tet $\mathrm{M}$ determinant occurs in $19-30 \%$ of $M$. hominis strains and seems to be increasing, making their therapeutic activities no longer predictable ${ }^{7,23,24}$. M. hominis is generally resistant to 14 - and 15-membered macrolides, but is susceptible to josamycin, a 16-membered macrolide ${ }^{25,26}$. Fluoroquinolones, which are frequently used for the treatment of upper genital tract infections, represent an effective alternative because they are the only bactericidal drugs against mycoplasmas. In recent years, $M$. hominis strains resistant to fluoroquinolones have also been reported ${ }^{27}$.

The results of our study indicate that cinnamon bark oil, carvacrol and eugenol possess bactericidal activity against $M$. hominis and could be used to treat mycoplasmal infections.

\section{ACKNOWLEDGMENT}

The study was supported by the Ministry of Education, Youth and Sports of the Czech Republic (Research Intention No. 0021627502 and SGFChT/2012).

\section{REFERENCES}

1. Dienes L, Edsall G. Observation on the L-organism of Klineberger Proc Soc Exp Biol Med 1937;36:740-4.

2. Bayraktar MR, Ozerol IH, Gucluer N, Celik O. Prevalence and antibiotic susceptibility of Mycoplasma hominis and Ureaplasma urealyticum in pregnant women. J Infect Dis 2009;14:90-5.

3. Daxboeck F, Zitta S, Stadler M, Iro E, Krause R. Mycoplasma hominis and Ureaplasma urealyticum in patients with sterile pyuria. J Infect 2005;51:54-8.

4. Phuah CL, Javid B, Aliyu SH, Lever AM. A case of Mycoplasma hominis septic arthritis postpartum. J Infect 2007;55:e135-7.

5. Marini H, Merle V, Frébourg N, Godier S, Bastit D, Benadiba L, Menguy E, Quesney M, Plissonnier D, Czernichow P. Mycoplasma hominis wound infection after a vascular allograft. J Infect 2008;57:272-4.

6. Hata A, Honda Y, Asada K, Sasaki Y, Kenri T, Hata D. Mycoplasma hominis meningitis in a neonate: case report and review. J Infect 2008;57:338-43.

7. Taylor-Robinson D, Bébéar C. Antibiotic susceptibilities of mycoplasmas and treatment of mycoplasmal infections. J Antimicrob Chemother 1997;40:622-30.

8. Waites KB, Katz B, Schelonka RL. Mycoplasmas and Ureaplasmas as neonatal pathogens. Clin Microbiol Rev 2005;18:757-89.

9. Yamaguchi M, Kikuchi A, Ohkusu K, Akashi M, Sasahara J, Takakuwa $\mathrm{K}$, Tanaka K. Abscess formation due to Mycoplasma hominis infection after caesarean section. J Obstet Gynaecol Res 2009;35:593-6.
10. Furneri PM, Marino A, Saija A, Uccella N, Bisignano G. In vitro antimycoplasmal activity of oleuropein. Int J Antimicrob Agents 2002;20:293-6.

11. Furneri PM, Piperno A, Sajia A, Bisignano G. Antimycoplasmal activity of hydroxytyrosol. Antimicrob Agents Chemother 2004;48:4892-4.

12. Furneri PM, Paolino D, Saija A, Marino A, Bisignano G. In vitro antimycoplasmal activity of Melaleuca alternifolia essential oil. J Antimicrob Chemother 2006;58:706-7.

13. Reichling J, Schnitzler P, Suschke U, Saller R. Essential oils of aromatic plants with antibacterial, antifungal, antiviral, and cytotoxic properties - an overview. Forsch Komp/ Med 2009;16:79-90.

14. Waites KB, Canupp KC, Kenny GE. In vitro susceptibilities of Mycoplasma hominis to six fluoroquinolones as determined by $\mathrm{E}$ test. Antimicrob Agents Chemother 1999;43:2571-3.

15. Bakkali F, Averbeck S, Averbeck D, Idaomar M. Biological effects of essential oils - A review. Food Chem Toxicol 2008;46:446-75.

16. Singh G, Maurya S, de Lampasona MP, Catalan CAN. A comparison of chemical, antioxidant and antimicrobial studies of cinnamon leaf and bark volatile oils, oleoresins and their constituents. Food Chem Toxicol 2007;45:1650-61.

17. Burt S. Essential oils: their antibacterial properties and potential applications in foods - a review. Int J Food Microbiol 2004;94:223-53.

18. Inouye S, Yamaguchi H, Takizawa T. Screening of the antibacterial effects of a variety of essential oils on respiratory tract pathogens, using a modified dilution assay method. J Infect Chemother 2001;7:251-4

19. Ben Arfa A, Combes S, Preziosi-Belloy L, Gontard N, Chalier P. Antimicrobial activity of carvacrol related to its chemical structure. Lett Appl Microbiol 2006;43:149-54.

20. Lambert RJW, Skandamis PN, Coote PJ, Nychas GJE. A study of the minimum inhibitory concentration and mode of action of oregano essential oil, thymol and carvacrol. Appl Microbiol 2001;91:453-62.

21. Santos AL, Chierice GO, Alexander KS, Riga A, Matthews E. Characterization of the raw essential oil eugenol extracted from Syzygium aromaticum L. J Therm Anal Calorim 2009;96:821-5.

22. Gill AO, Holley RA. Disruption of Escherichia coli, Listeria monocytogenes and Lactobacillus sakei cellular membranes by plant oil aromatics. Int J Food Microbiol 2006;108:1-9.

23. Dégrange $S$, Renaudin $H$, Charron A, Bébéar $C$, Bébéar CM. Tetracycline resistance in Ureaplasma spp. and Mycoplasma hominis: Prevalence in Bordeaux, France, from 1999 to 2002 and description of two tet(M)-positive isolates of $M$. hominis susceptible to tetracyclines. Antimicrob Agents Chemother 2008;52:742-4.

24. Taraskina AE, Savicheva AM, Akopian TA, Soroka AE, Momynaliev KT, Govorun VM. Drift of tetM determinant in urogenital microbiocenosis containing mycoplasmas during treatment with a tetracycline antibiotic. Bull Exp Biol Med 2002;134:60-3.

25. Karamova AE, Polyakov, AV, Komarova NV. Detection of mutant Mycoplasma hominis strains resistant to 16-membered macrolide antibiotic josamycin in clinical samples. Bull Exp Biol Med 2004; 137:483-4.

26. Pereyre $S$, Renaudin $H$, Charron A, Bébéar $C$, Bébéar CM. Emergence of a $23 \mathrm{~S}$ rRNA mutation in Mycoplasma hominis associated with a loss of the intrinsic resistance to erythromycin and azithromycin. J Antimicrob Chemother 2006;57:753-6.

27. Bebear CM, Bové JM, Bebear C, Renaudin J. Characterization of Mycoplasma hominis mutations involved in resistance to fluoroquinolones. Antimicrob Agents Chemother 1997;41:269-73. 